\title{
Urea-induced ROS generation causes insulin resistance in mice with chronic renal failure
}

\author{
Maria D'Apolito, ${ }^{1}$ Xueliang Du,, ${ }^{2}$ Haihong Zong, ${ }^{2}$ Alessandra Catucci, ${ }^{1}$ Luigi Maiuri, ${ }^{1}$ \\ Tiziana Trivisano, ${ }^{3}$ Massimo Pettoello-Mantovani, ${ }^{1}$ Angelo Campanozzi, ${ }^{1}$ \\ Valeria Raia, ${ }^{4}$ Jeffrey E. Pessin, ${ }^{2}$ Michael Brownlee, ${ }^{2}$ and Ida Giardino ${ }^{3}$
}

${ }^{1}$ Institute of Pediatrics, University of Foggia, Foggia, Italy. ${ }^{2}$ Diabetes Research Center, Albert Einstein College of Medicine, New York, New York, USA. ${ }^{3}$ Department of Biomedical Science, University of Foggia, Foggia, Italy. ${ }^{4}$ Department of Pediatrics, Federico II University, Naples, Italy.

\begin{abstract}
Although supraphysiological concentrations of urea are known to increase oxidative stress in cultured cells, it is generally thought that the elevated levels of urea in chronic renal failure patients have negligible toxicity. We previously demonstrated that ROS increase intracellular protein modification by $O$-linked $\beta$ - $N$-acetylglucosamine (O-GlcNAc), and others showed that increased modification of insulin signaling molecules by O-GlcNAc reduces insulin signal transduction. Because both oxidative stress and insulin resistance have been observed in patients with end-stage renal disease, we sought to determine the role of urea in these phenotypes. Treatment of 3T3-L1 adipocytes with urea at disease-relevant concentrations induced ROS production, caused insulin resistance, increased expression of adipokines retinol binding protein 4 (RBP4) and resistin, and increased O-GlcNAc-modified insulin signaling molecules. Investigation of a mouse model of surgically induced renal failure (uremic mice) revealed increased ROS production, modification of insulin signaling molecules by O-GlcNAc, and increased expression of RBP4 and resistin in visceral adipose tissue. Uremic mice also displayed insulin resistance and glucose intolerance, and treatment with an antioxidant $\mathrm{SOD} /$ catalase mimetic normalized these defects. The SOD/catalase mimetic treatment also prevented the development of insulin resistance in normal mice after urea infusion. These data suggest that therapeutic targeting of urea-induced ROS may help reduce the high morbidity and mortality caused by end-stage renal disease.
\end{abstract}

\section{Introduction}

Elevated urea in chronic renal failure (CRF) is considered to have negligible toxicity because Johnson et al. found in 1972 that in patients with far-advanced renal failure, blood urea concentrations of less than $50 \mathrm{mM}$ (blood urea nitrogen [BUN] of $140 \mathrm{mg} / \mathrm{dl}$ ) were well tolerated when blood urea concentration was maintained by adding urea to the dialysate solution (1) and 30 years later, the HEMO study showed that increasing urea reduction rate from $66 \%$ to $75 \%$ did not alter survival in patients with an increased dialysis dose (2). However, more recent data have demonstrated that survival of patients on daily hemodialysis is 2- to 3-fold greater than that of patients dialyzed less frequently (3). The observation that in an animal model of CRF-accelerated atherosclerosis (4), plasma urea was the only significant predictor of aortic plaque area fraction suggested to us that the high levels of urea found in chronic dialysis patients might play an important role in accelerated atherosclerosis in this group of patients.

Nonphysiologic concentrations of urea have been reported to increase levels of ROS and the oxidative stress marker 8-oxoguanine in cultured IMCD3 cells (5). End-stage renal disease (ESRD) patients have increased levels of oxidative stress (6), and we have shown previously that intracellular ROS induced by hyperglycemia increase protein modification by $O$-linked $\beta$ - $N$-acetylglucosamine (O-GlcNAc) (7). Increased modification of key signaling molecules by O-GlcNAc was recently shown to cause reduced insulin signal transduction (8). Insulin resistance is a well-documented feature

Authorship note: Xueliang Du and Haihong Zong, as well as Michael Brownlee and Ida Giardino, contributed equally to this work.

Conflict of interest: The authors have declared that no conflict of interest exists. Citation for this article: J. Clin. Invest. 120:203-213 (2010). doi:10.1172/JCI37672. of ESRD, and the rate of death among hemodialysis patients is greater in those with more severe insulin resistance (9). The insulin resistance present in ESRD appears to start much earlier in the course of chronic kidney disease, when renal failure is subclinical (10). Although the cause of insulin resistance in chronic renal disease is unknown (11), several abnormalities associated with ESRD might interfere with insulin signaling (12-17). We therefore hypothesized that concentrations of urea associated with CRF might drive insulin resistance by increasing ROS production, thereby increasing modification of insulin signaling molecules by O-GlcNAc. In this study, we have observed that uremic mice are insulin resistant and glucose intolerant, with increased plasma levels of 2 insulin resistance-associated adipokines: retinol binding protein 4 (RBP4) and resistin. In cultured 3T3-L1 adipocytes, urea caused decreased insulin sensitivity and increased adipokine secretion due to ROS-induced increases in O-GlcNAc modification of insulin signaling molecules. In uremic mice, treatment with a SOD/catalase mimetic normalized both O-GlcNAc modification of insulin signaling molecules and the increased insulin resistance-associated adipokine expression in visceral adipose tissue, correcting systemic insulin resistance and glucose intolerance. Finally, urea infusion in normal animals induced the same degree of insulin resistance and elevated insulin resistance-associated adipokines seen in uremic mice, while concomitant SOD/catalase mimetic treatment completely prevented insulin resistance and elevated adipokines induced by urea infusion.

\section{Results}

Uremic mice are insulin resistant and glucose intolerant and have elevated plasma levels of insulin resistance-associated adipokines. Body weight and food intake did not differ between the uremic and nonuremic 
Table 1

Uremic mice have an insulin-resistant phenotype

\begin{tabular}{lccc}
\hline & C57BL/6J & Uremic C57BL/6J & $\boldsymbol{P}$ \\
Plasma urea $(\mathrm{mmol} / \mathrm{l})$ & $9.4 \pm 1$ & $26.4 \pm 1.7$ & $<0.01$ \\
Plasma insulin $(\mathrm{pg} / \mathrm{ml})$ & $262.04 \pm 29.63$ & $1680 \pm 4.34$ & $<0.01$ \\
Plasma glucose $(\mathrm{mg} / \mathrm{dl})$ & $90.75 \pm 6.22$ & $122.66 \pm 20.597$ & $\mathrm{NS}$ \\
Plasma cholesterol $(\mathrm{mg} / \mathrm{dl})$ & $64.27 \pm 2.4$ & $166.38 \pm 18.05$ & $<0.01$ \\
Plasma triglycerides $(\mathrm{mg} / \mathrm{dl})$ & $53.51 \pm 4.7$ & $102.63 \pm 10.28$ & $<0.01$ \\
\hline
\end{tabular}

Results are expressed as mean \pm SEM; $n=34$.

mice throughout the study. In CRF mice, the serum plasma urea concentration was increased 2.8 -fold 2 weeks after $5 / 6$ nephrectomy (Table 1). Remarkably, in uremic mice, the fasting plasma insulin levels were more than 6 times higher than those of nonuremic mice, while the plasma glucose concentration trended toward an increase but was not significantly different between the 2 groups (Table 1), suggesting the presence of insulin resistance. Consistent with an insulin-resistant phenotype (18), plasma triglyceride and cholesterol levels were both significantly increased in the uremic mice (Table 1). To quantify the degree of insulin resistance and glucose intolerance induced by uremia, i.p. insulin and glucose tolerance tests were performed (Figure 1). As shown in Figure 1A, the decrease in plasma glucose 60 minutes after insulin injection was half that in nonuremic mice. Similarly, in uremic mice, elevated plasma glucose remained unchanged 120 minutes after glucose injection (Figure 1B). In control mice, glucose values returned to baseline by 120 minutes while in uremic mice, glucose values remained more than twice baseline values (Figure 1D). Uremic mice had plasma insulin levels 6.4-fold higher than control mice at 0 minutes and 8.6-fold higher than control mice 120 minutes after glucose injection (Figure 1C). Plasma insulin levels correlated closely with plasma urea levels $\left(r^{2}=0.8 ; \mathrm{P}<0.01\right)$. Since elevated plasma levels of the insulin resistance-associated adipokines RBP4 and resistin are observed in CRF patients (19, 20 ), concentrations of RBP4 and resistin were measured in the plasma of uremic CRF and control mice. In uremic mice, plasma RBP4 concentration was increased 2.8-fold (Figure 2A) and plasma resistin levels were 1.7 -fold higher compared with those of control mice (Figure 2B).

Urea reduces insulin-stimulated glucose transport in 3T3-L1 adipocytes by altering phosphorylation of insulin signaling molecules. In order to determine whether elevated urea was the cause of insulin resistance in uremic mice, insulin-stimulated uptake of [1-3H] 2-deoxyglucose was measured in differentiated 3T3-L1 cells. A concentration-response relationship between urea and impaired insulin signaling was observed between $10 \mathrm{mM}$ and $40 \mathrm{mM}$ urea (Supplemental Figure 1A; supplemental material available online with this article; doi:10.1172/ JCI37672DS1). Remarkably, after incubation with a urea concentration similar to that in uremic mice $(20 \mathrm{mM})$ for 48 hours, insulin-stimulated glucose transport was reduced by $76.4 \%$, whereas mannitol, used as an osmotic control, had no effect on insulin-stimulated glucose transport (Figure 3A). To investigate the mechanism underlying this urea-induced inhibition of insulin-stimulated glucose transport, cell lysates were prepared from adipocytes exposed to insulin alone and to insulin plus $20 \mathrm{mM}$ urea. IRS-1 was immunoprecipitated and blotted for total phosphotyrosine, which activates insulin signaling, and for IRS-1
A
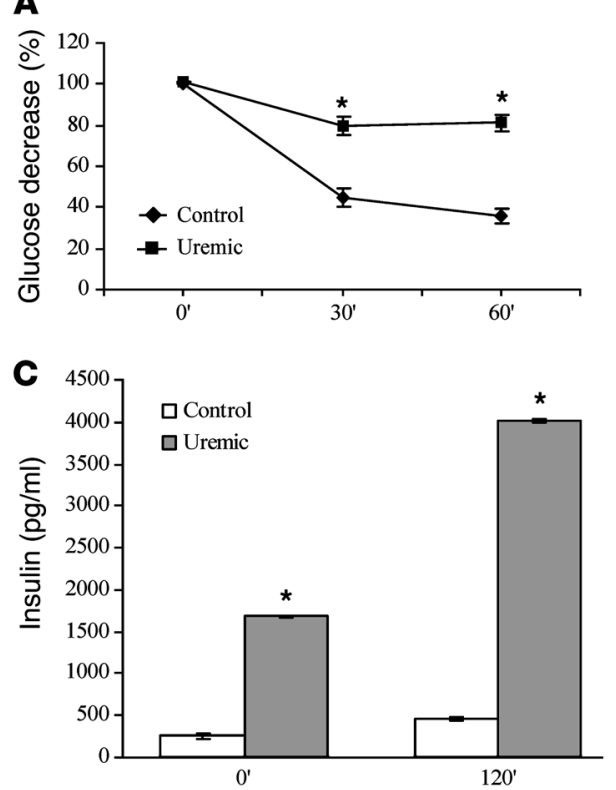

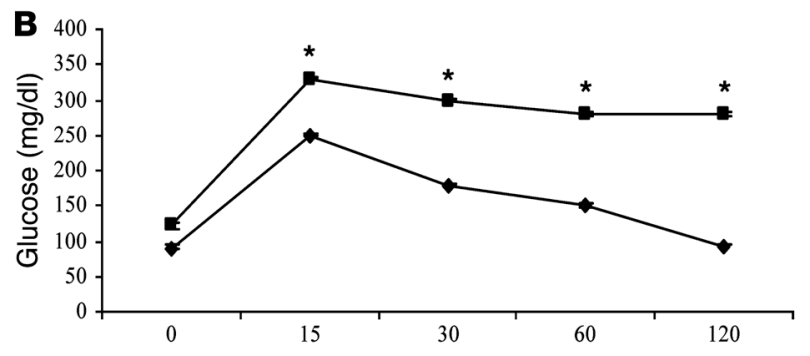

D

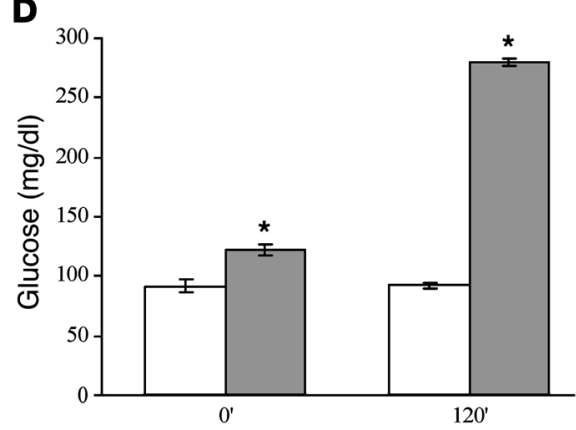

Figure 1

Uremic mice are insulin resistant and glucose intolerant. (A) Insulin tolerance test. Mice were injected i.p. with insulin (0.75 U/kg), and blood glucose was measured at 0, 30, and 60 minutes. (B) i.p. glucose tolerance test. Mice were injected i.p. with glucose (1 mg/g body weight), and blood glucose was measured at 0, 15, 30, 60, and 120 minutes. (C) Insulin resistance in uremic mice. Insulin values from the IPGTT animals shown in B were determined by ELISA. (D) Glucose intolerance in uremic mice. Glucose values from B at 0 and 120 minutes. All results represent mean \pm SEM of 9 animals per group. ${ }^{*} P<0.01$ compared with controls. 

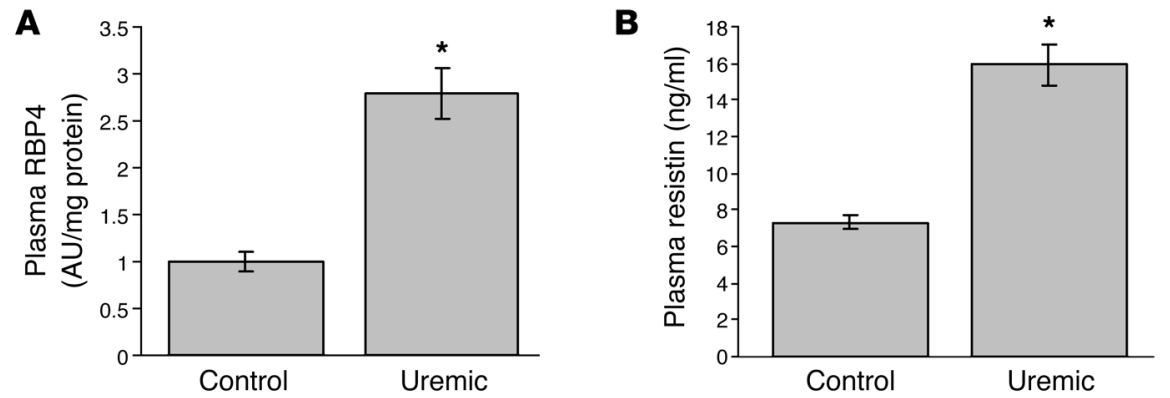

\section{Figure 2}

Uremic mice have elevated plasma levels of insulin resistance-associated adipokines. Plasma RBP4 (A) and resistin (B) concentrations were measured in the plasma of control and uremic mice by semiquantitative Western blot (A) or ELISA (B). Each bar represents the mean \pm SEM of 9 mice per group. ${ }^{*} P<0.01$ compared with controls.

Ser636 phosphorylation, which functionally inhibits IRS-1 activity (8). As shown in Figure 3B, urea reduced insulin-dependent IRS-1 tyrosine phosphorylation by $60 \%$, while it increased Ser636 phosphorylation by $70 \%$. Akt was also immunoprecipitated and blotted for pSer473 (Figure 3C). As with IRS-1, urea reduced insulin-dependent phosphorylation of Ser 473 by $46 \%$. Urea treatment did not impair the ability of insulin to stimulate insulin receptor autophosphorylation (data not shown).

Urea-induced decrease in insulin-stimulated glucose transport is mediated by mitochondrial ROS. Nonphysiologic concentrations of urea have been shown to increase free radical generation in renal inner medullary cells (5). We found that urea at a concentration similar to that in uremic mice $(20 \mathrm{mM})$ increases ROS levels in 3T3-L1 adipocytes by 2.9-fold, and insulin had no effect on this urea-induced ROS generation (Figure 4A and Supplemental Figure 1A). Since increased ROS levels appear to increase insulin resistance in several physiologic contexts (21), we evaluated the effect of overexpressing various antioxidant enzymes on the urea-induced decrease in insulin-stimulated glucose transport (Figure 4B). Catalase, a heme protein located predominantly in peroxisomes and the inner mitochondrial membrane, catalyzes the conversion of $\mathrm{H}_{2} \mathrm{O}_{2}$ to $\mathrm{H}_{2} \mathrm{O}$. Overexpression of catalase normalized both urea-induced ROS generation (Figure 4A) and insulin-stimulated glucose transport (Figure 4B). This suggests that overproduction of $\mathrm{H}_{2} \mathrm{O}_{2}$ plays a critical role in urea-induced insulin resistance. Since increased $\mathrm{H}_{2} \mathrm{O}_{2}$ production could reflect functional alterations in mitochondria, endoplasmic reticulum, or a number of NADPH-dependent oxidases, we next overexpressed 2 enzymes that specifically prevent mitochondrial ROS production: uncoupling protein-1 (UCP1), which collapses the proton electrochemical gradient driving mitochondrial ROS production, and manganese SOD2 (MnSOD2), the mitochondrial form of this antioxidant enzyme. Each of these 2 enzymes normalized urea-induced free radical generation (Figure 4A) and completely prevented urea-induced insulin resistance in 3T3-L1 adipocytes (Figure 4B). Together, these data indicate that mitochondrial superoxide overproduction is responsible for the observed insulin resistance in 3T3-L1 adipocytes.

\section{Figure 3}

Urea causes decreased insulin sensitivity in differentiated 3T3L1 adipocytes. (A) Effect of urea on insulin-stimulated glucose uptake in differentiated 3T3L1 cells. (B) Immunoblot analysis of insulin-induced phosphorylation of IRS-1 tyrosine and Ser636 in urea-treated 3T3L1 cells and controls. (C) Immunoblot analysis of insulin-induced AKT phosphorylation in urea-treated $3 \mathrm{~T} 3 \mathrm{~L} 1$ cells and their controls. Maximum levels of IRS-1 and AKT phosphorylation are shown as $100 \%$ in bar graphs.IP, immunoprecipitation. $n=5$; ${ }^{*} P<0.01$ compared with controls. Data represent mean \pm SEM.
Urea-induced ROS modify IRS-1 by O-GlcNAc. Increased mitochondrial superoxide production has been shown to activate the hexosamine pathway, which results in increased modification of intracellular proteins by O-GlcNAc. Recently, it has been reported that modification of the insulin signaling pathway by O-GlcNAc results in altered phosphorylation of key signaling molecules that attenuated insulin signal transduction (8). As shown in Figure 5A,

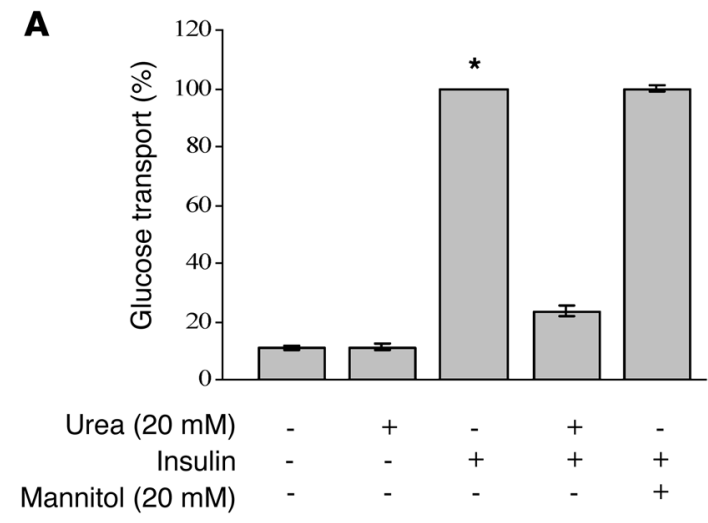

$\mathbf{B}$
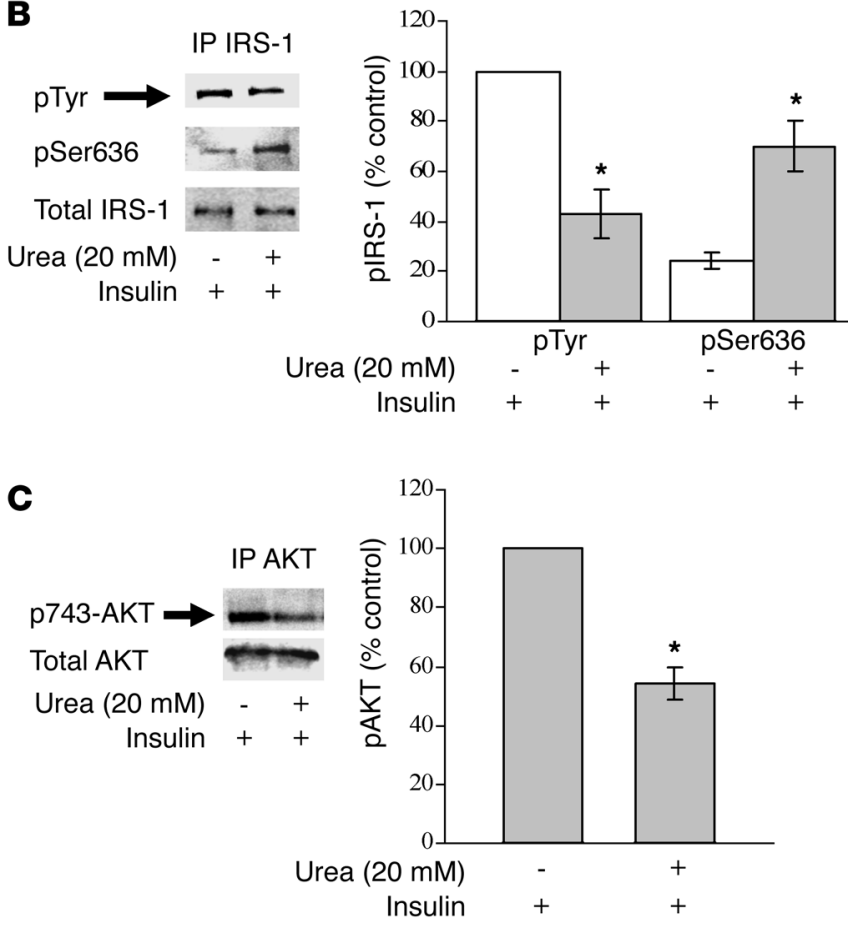

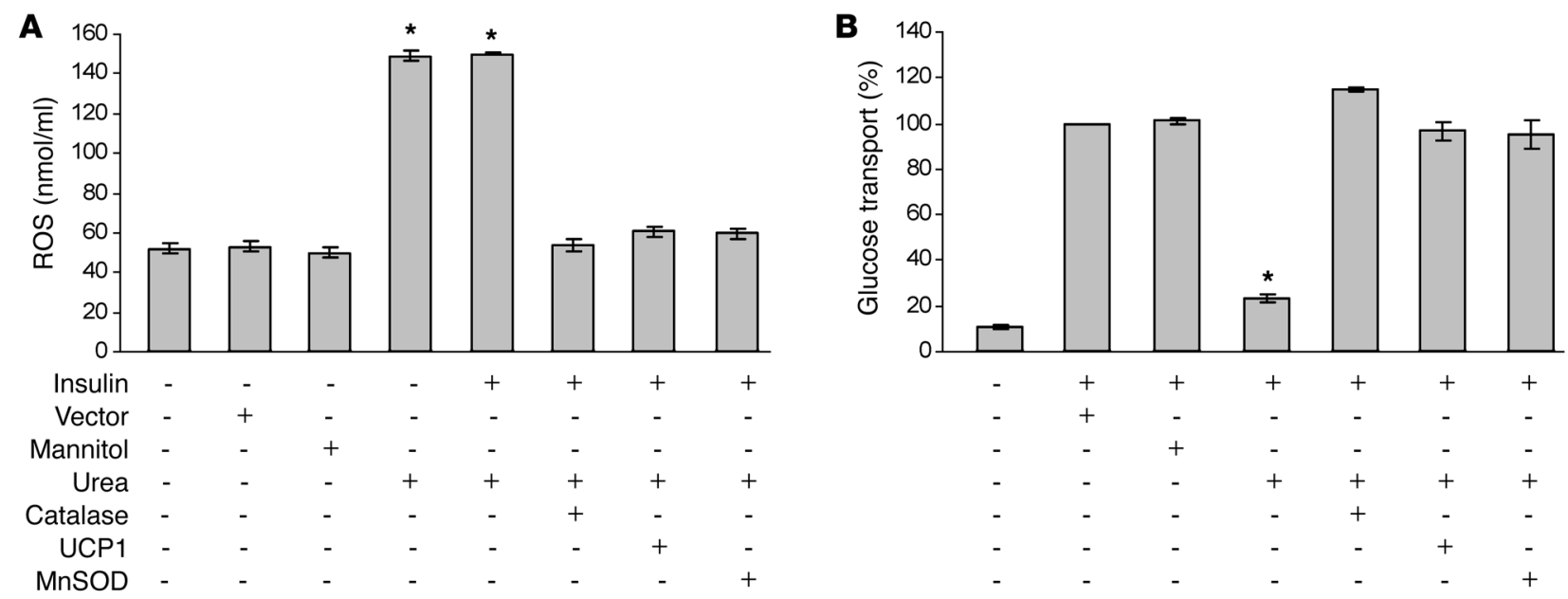

\section{Figure 4}

Urea-induced decrease in insulin-stimulated glucose transport is mediated by mitochondrial ROS. Cells were infected with adenoviral vectors expressing catalase, UCP1, or MnSOD. After 48 hours incubation with urea, both intracellular ROS generation (A) and insulin-stimulated glucose uptake (B) were measured. Each bar represents the mean \pm SEM of 5 separate experiments, each with $n=8$. ${ }^{*} P<0.01$ compared respectively with cells not treated with urea $(\mathbf{A})$ or with insulin $(\mathbf{B})$.

urea treatment doubled IRS-1 modification by O-GlcNAc. This increase was completely prevented by overexpression of catalase, UCP1, or MnSOD (Figure 5B).

Urea-induced ROS increase expression and secretion of insulin resistance-associated adipokines. As shown in Figure 2, plasma levels of RBP4 and resistin were increased in uremic mice. In 3T3-L1 adi- pocytes, urea exposure increased RBP4 expression by 2.5 -fold and resistin expression by 2 -fold (Figure 6A). Levels of RBP4 and resistin secreted into the medium by cells exposed to urea were 1.7 -fold and 3-fold higher, respectively, than those from cells exposed to insulin alone (Figure 6B). Overexpression of catalase, MnSOD, or UCP1 completely prevented the urea-induced increase in expres-
A
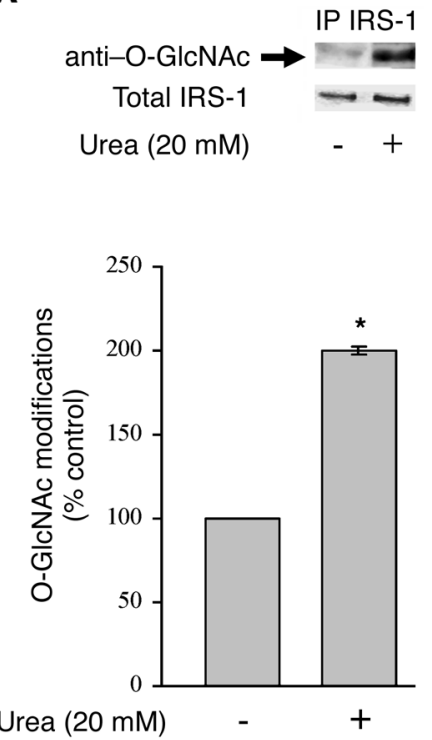

B
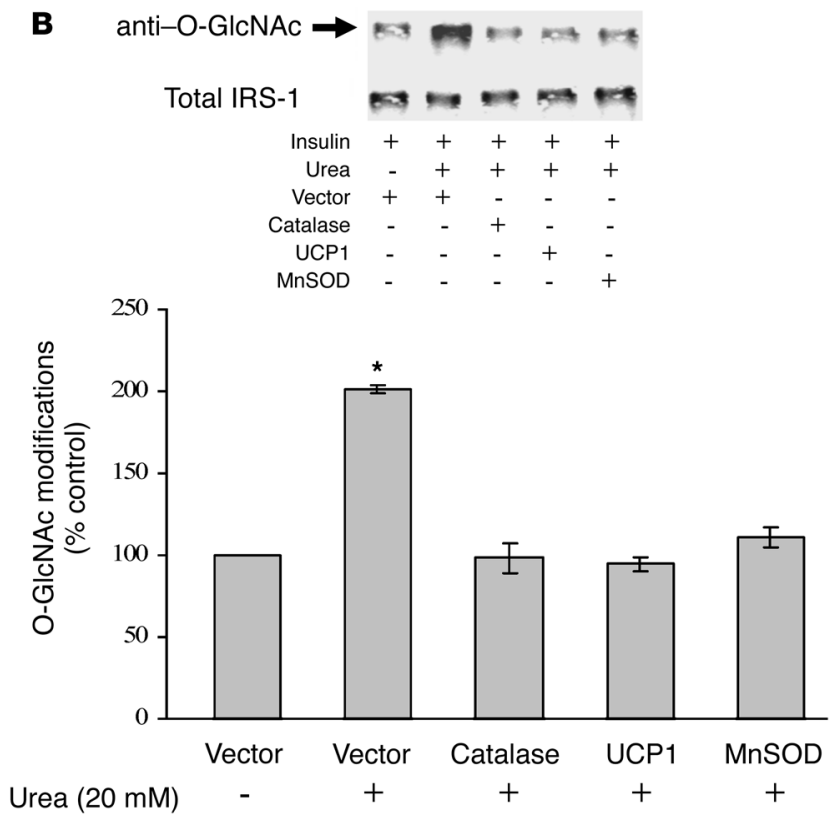

Figure 5

Urea-induced ROS increase IRS-1 modification by O-GIcNAc in 3T3L1 adipocytes. (A) IP Western blot analysis of IRS-1 modification by O-GIcNAc in urea-treated 3T3L1 cells (48 hours) and their controls. (B) IP Western blot analysis of IRS-1 modification by O-GIcNAc in ureatreated 3T3-L1 cells alone and after overexpression of catalase, UCP1, and MnSOD. Cells were infected with adenoviral vectors expressing catalase, UCP1, or MnSOD. After incubation with urea for 48 hours, IRS-1 was immunoprecipitated and the amount of O-GIcNAc modification was analyzed by immunoblotting. Levels of modification in cells infected with empty vector are shown as $100 \%$ in bar graphs. $n=5$; ${ }^{\star} P<0.01$ compared with controls. Data represent mean \pm SEM. 


\section{A}

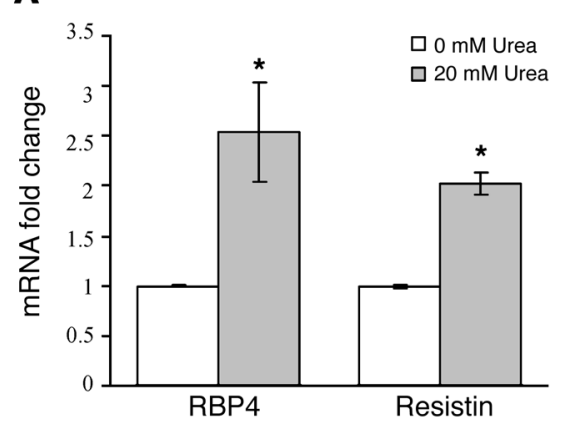

c

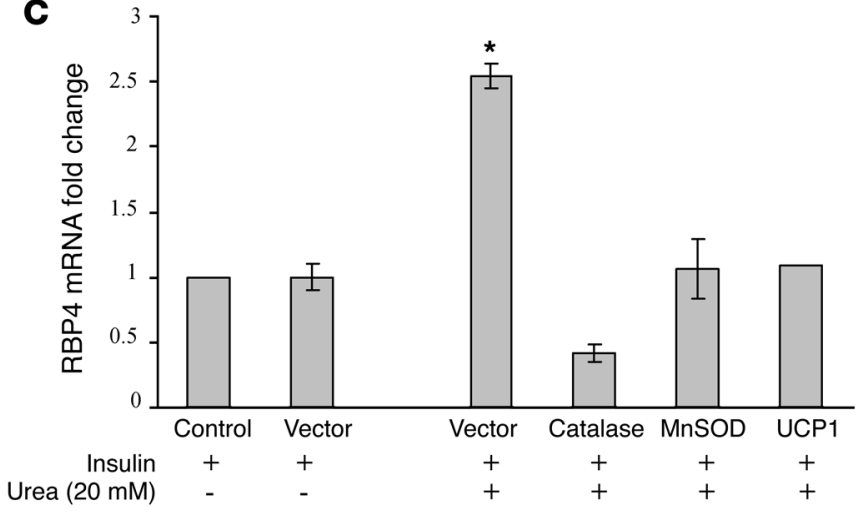

D

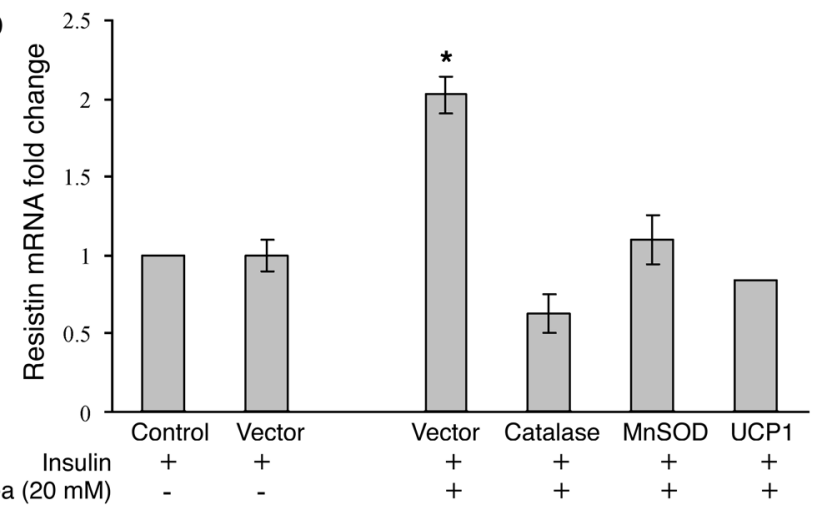

\section{Figure 6}

Urea-induced ROS increase expression and secretion of insulin resistance-associated adipokines in 3T3L1 adipocytes. (A) Effect of urea on RBP4 and resistin mRNA. Adipokine expression was evaluated by quantitative PCR (qPCR) in cells exposed to urea for 48 hours and in control cells. (B) Effect of urea on RBP4 and resistin protein secreted in the medium by 3T3L1 adipocytes. RBP4 and resistin concentration were measured by ELISA. (C and D) Effect of catalase, MnSOD, and UCP1 overexpression on urea-induced increases in RBP4 (C) and resistin (D) expression. Cells were infected with adenoviral vectors as described above and adipokine expression measured by qPCR. Results are expressed as fold changes versus the controls. Each bar represents the mean \pm SEM of 5 different experiments. ${ }^{*} P<0.01$ compared with controls.

sion of RBP4 (Figure 6C) and resistin (Figure 6D). These results confirm that urea-induced ROS, which cause adipocyte insulin resistance, directly increase expression and secretion of the insulin resistance-associated adipokines RBP4 and resistin from 3T3-L1 adipocytes in a cell-autonomous manner.

Treatment of uremic mice with a SOD/catalase mimetic normalizes byperinsulinemia, insulin resistance, and glucose intolerance in uremic mice. To determine in vivo the effect of uremia-generated ROS on insulin resistance and glucose tolerance, CRF mice and their controls were treated for 2 weeks with daily injections of the SOD/ catalase mimetic tetrakis (4-benzoic acid) porphyrin (MnTBAP). MnTBAP has catalytic activities similar to the ROS-scavenging enzymes SOD and catalase. It protects mammalian cells from oxidative damage and complements loss-of-function SOD mutations in bacteria and mice (22). MnTBAP administration did not have any effect on plasma urea levels in either control or uremic mice (Figure 7A). Similarly, treatment with MnTBAP had no effect on plasma glucose levels in either control or uremic mice (Figure 7B). However, despite the lack of change in plasma urea levels, MnTBAP completely prevented the 6-fold increase in insulin plasma levels caused by CRF (MnTBAP-treated uremic mice $[262.0 \pm 29.6 \mathrm{pg} / \mathrm{ml}]$ versus untreated uremic mice [1680 \pm 4.3$]$; $P<0.01)$. Fasting plasma insulin concentration in uremic mice treated with MnTBAP was not statistically different from the concentration measured in sham-operated mice $(262 \pm 29.63 \mathrm{pg} / \mathrm{ml}$ versus $265 \pm 29.7 \mathrm{pg} / \mathrm{ml}$ ) (Figure 7C).

This normalization of insulin levels in MnTBAP-treated uremic mice was associated with normalization of both insulin resistance and abnormal glucose tolerance (Figure 8). Treatment of uremic mice with MnTBAP completely normalized their insulin tolerance tests (Figure 8A). Similarly, glucose tolerance in uremic mice was completely normalized by MnTBAP treatment (Figure 8, B and D). In these mice, serum insulin levels were normalized at both 0 minutes and 120 minutes after glucose injection (Figure 8C), and serum glucose was normalized at 120 minutes (Figure 8D).

Treatment of uremic mice with a $S O D /$ catalase mimetic normalizes oxidative stress, IRS-1 O-GlcNAc modification, and IRS-1 tyrosine phosphorylation. Since urea-induced ROS caused insulin resistance in 3T3-L1 adipocytes by increasing IRS-1 modification by O-GlcNAc and reducing IRS- 1 tyrosine phosphorylation, we examined these parameters in adipose tissue of uremic mice. In epididymal fat, the level of oxidative stress was determined by measuring protein nitration. As shown in Figure 9A, the level of protein nitration was increased over 6-fold in adipose tissue from uremic mice. Treatment of uremic mice with MnTBAP completely normalized adipose tissue protein nitration. IRS-1 modification by O-GlcNAc 
A

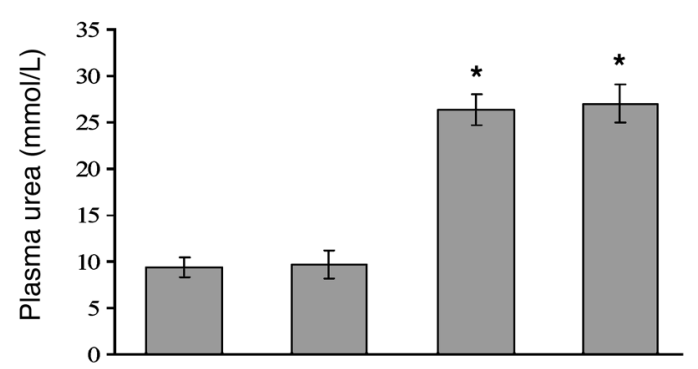

B

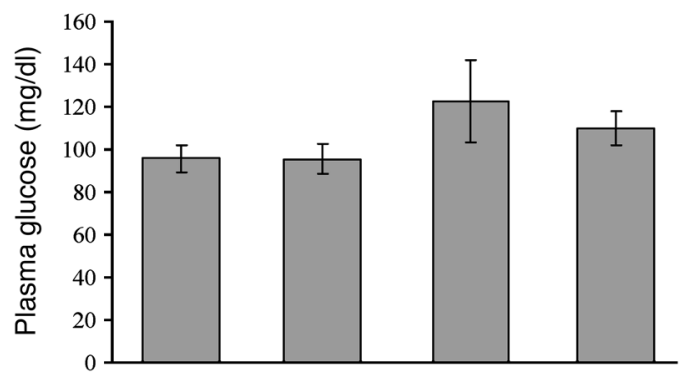

C

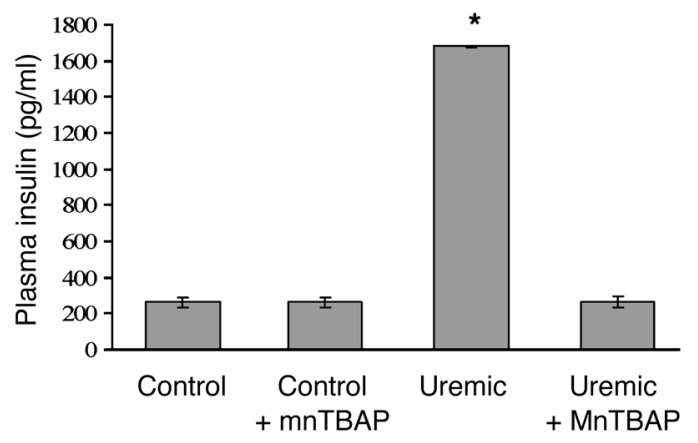

in adipose tissue of uremic mice was increased 1.5-fold (Figure 9B), similar to our findings in urea-exposed 3T3-L1 adipocytes, while IRS- 1 tyrosine phosphorylation was reduced by nearly $40 \%$ in adipose tissue of the uremic animals (Figure 9C). Treatment of uremic mice with MnTBAP completely prevented the uremiainduced increase in IRS-1 modification by O-GlcNAc and completely restored the insulin-dependent IRS- 1 tyrosine phosphorylation to the same level found in epididymal adipose tissue of control mice (Figure 9, B and C).

Treatment of uremic mice with a SOD/catalase mimetic normalizes insulin resistance-associated adipokines. Since urea-induced insulin resistance in 3T3-L1 adipocytes increased expression and secretion of RBP4 and resistin, we next examined the expression of these 2 insulin resistance-associated adipokines in epididymal fat of uremic mice. As shown in Figure 10A, the levels of RBP4 and resistin mRNA expression were increased $9.0 \pm 3.3$-fold and $4.1 \pm 0.5$-fold, respectively, compared with the levels in epididymal adipose tissue of control mice.

Treatment of uremic mice with MnTBAP normalized adipose RBP4 expression and decreased resistin expression by $66 \%$ (Figure 10A). In parallel, elevated plasma levels of RBP4 and resistin in uremic mice were completely normalized by MnTBAP treatment (Figure 10B). Additionally, as observed in human patients (19), uremic mice displayed an increase in total adiponectin levels (Supplemental Figure 2A) that was completely reversed by treatment with MnTBAP (Supplemental Figure 2B).

\section{Figure 7}

Treatment of uremic mice with a SOD/catalase mimetic normalizes hyperinsulinemia. (A) Effect of MnTBAP on uremia. After 2 weeks of treatment with MnTBAP, plasma urea concentration was measured in untreated and MnTBAP-treated control mice and in untreated and MnTBAP-treated uremic mice. Results represent the mean \pm SEM of 7 animals per group. ${ }^{*} P<0.01$ compared with controls. (B) Effect of MnTBAP on plasma glucose in uremic mice. After 2 weeks of treatment with MnTBAP, plasma glucose was measured in the indicated groups of mice. Results represent mean \pm SEM of 7 animals per group. (C) Effect of MnTBAP on uremia-induced hyperinsulinemia in uremic mice. After 2 weeks of treatment with MnTBAP, plasma insulin concentration was measured by ELISA in untreated and MnTBAP-treated control mice and in untreated and MnTBAP-treated uremic mice. The results represent mean \pm SEM of 7 animals per group. ${ }^{*} P<0.01$ compared with controls.

Urea infusion in normal animals induces insulin resistance and elevates insulin resistance-associated adipokines. The data presented in Figures 8-10 demonstrate that partially nephrectomized mice exhibit high plasma urea and insulin resistance, which is completely reversed by MnTBAP treatment. In order to demonstrate that elevated urea actually causes insulin resistance in vivo, urea was infused in normal animals and insulin resistance was determined during euglycemic hyperinsulinemic (EU) clamps (23). Urea was infused for 48 hours prior to the EU clamp, and the steady-state urea concentration in urea-infused animals was 2.9-fold higher than in isotonic saline-infused animals (data not shown), similar to the 2.8 -fold increase in urea concentration observed in our CRF model (Table 1). Insulin levels at time zero of the clamps was nearly 2 -fold elevated in the uremic animals ( 0.08 versus $0.14 \mu \mathrm{g} / \mathrm{ml}$ ) but was identical (2.1 versus $2.2 \mu \mathrm{g} / \mathrm{ml}$ ) during the EU clamp. The glucose infusion rate (GIR) necessary to maintain euglycemia was significantly decreased in the urea-infused animals (Figure 11, A and B), indicating marked whole-body insulin resistance (24). Treatment with MnTBAP completely reversed the urea-induced insulin resistance, with the GIR necessary to maintain euglycemia not statistically different from that of saline-infused animals. Urea-induced insulin resistance was associated with a greater than 2.5 -fold increase in plasma levels of the insulin resistance-associated adipokines RBP4 (Figure 11C) and resistin (Figure 11D), similar to the fold increase observed in uremic mice (Figure 2). Moreover, MnTBAP treatment also prevented the urea-induced elevation of blood levels of the insulin resistance-associated adipokines RBP4 (Figure 11C) and resistin (Figure 11D). The urea infusion conditions sufficient to induce insulin resistance did not induce hemolysis or osmotic diuresis, 2 potentially confounding variables. These data demonstrate that urea alone is sufficient to induce the same degree of insulin resistance and elevated insulin resistance-associated adipokines seen in uremic mice and that insulin resistance and elevated serum adipokines in the urea-infused normal rats are caused by urea-induced ROS.

\section{Discussion}

In nonuremic people with normal glucose tolerance, insulin resistance markedly increases cardiovascular disease risk, even after adjustment for known risk factors such as LDL, triglycerides, $\mathrm{HDL}$, and systolic blood pressure $(25,26)$. In dialysis patients, the cardiovascular mortality rate is approximately 30 times the risk in the general population and remains 10 to 20 times higher even after stratification for age, sex, and presence of diabetes (27). Over- 
A
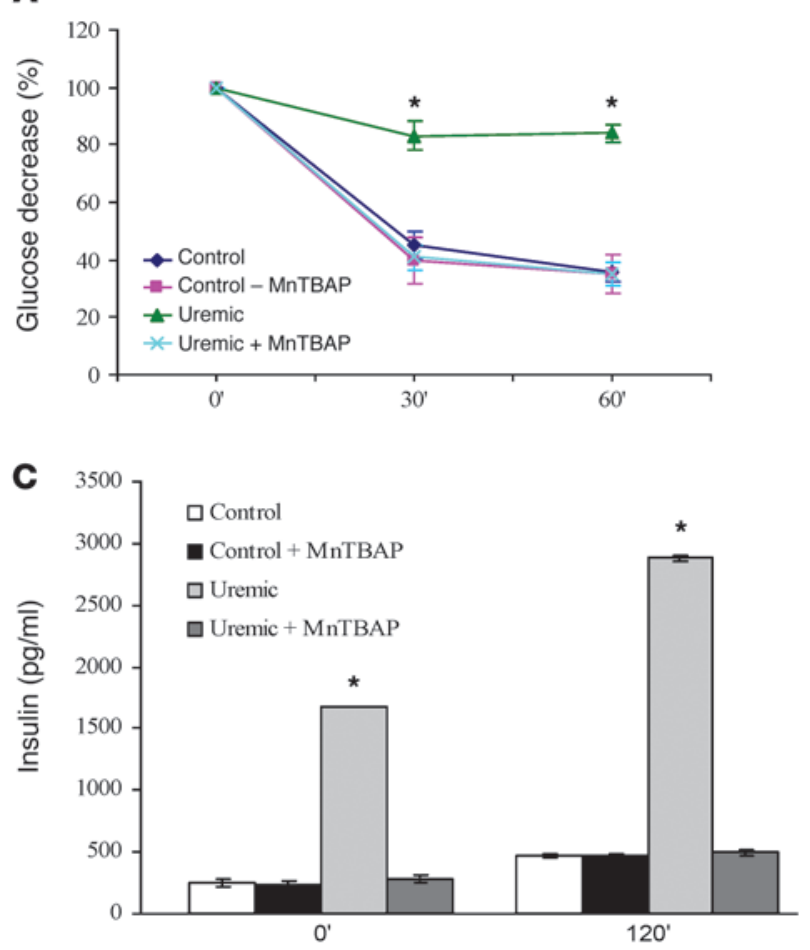
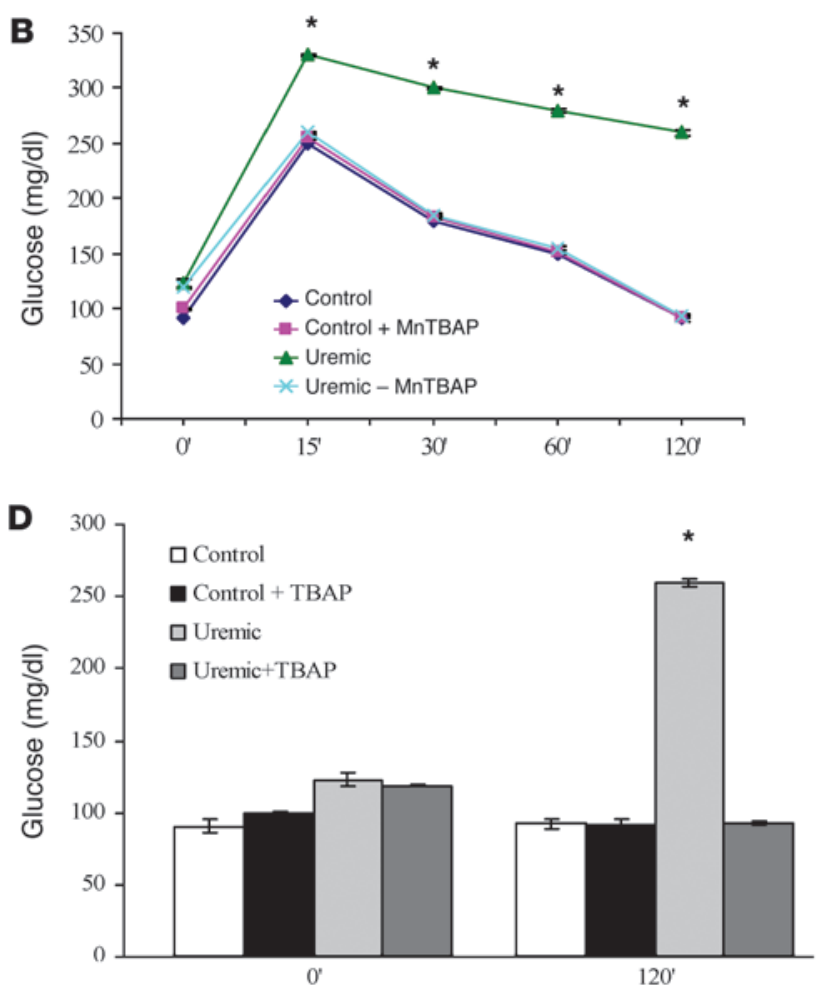

Figure 8

Treatment of uremic mice with a SOD/catalase mimetic normalizes insulin resistance and glucose intolerance. Treated uremic mice and treated controls received MnTBAP i.p. for 2 weeks. (A) Insulin tolerance test. Mice were injected i.p. with insulin (0.75 U/kg), and blood glucose was measured at 0, 30, and 60 minutes. (B) i.p. glucose tolerance test. Mice were injected i.p. with glucose (1 mg/g body weight), and blood glucose was measured at 0, 15, 30, 60, and 120 minutes. (C) Insulin resistance in uremic mice. Insulin values from the IPGTT animals shown in B were determined by ELISA. (D) Glucose intolerance in uremic mice. Glucose values from B at 0 and 120 minutes. All results represent mean \pm SEM of 7 animals per group. ${ }^{*} P<0.01$ compared with controls.

all, the 5-year mortality rate for patients on dialysis is $60 \%$ (28). CRF itself appears to be a significant contributing cause of this accelerated atherosclerosis, since even young, nondiabetic adults on chronic hemodialysis have increased intimamedia thickening, arterial stiffness, and coronary artery calcification (29-31). The rate of death among hemodialysis patients is higher in those with more severe insulin resistance (9).

Due to the lack of correlation with symptoms of the uremic syndrome after addition of urea to dialysate (1) and the lack of impact on survival in patients whose urea reduction rate was increased from $66 \%$ to $75 \%$ by increased dialysis dose (2), it has been assumed that elevated levels of urea in CRF have negligible toxicity. However, more recent data show that survival of patients on daily hemodialysis is 2- to 3-fold greater than that of patients dialyzed less frequently (3). Reduction in several insulin resistance metabolic markers was associated with improved mortality in patients on daily dialysis, including hyperhomocysteinemia, dyslipidemia, hypoalbuminemia, and hormonal abnormalities (3). ESRD patients also have increased levels of oxidative stress (6), and reduction of oxidative stress results in a number of beneficial effects (32-34). Experimental CRF-accelerated atherosclerosis was prevented by treatment with the antioxidant $\mathrm{N}$-acetylcysteine, and plasma urea level was the only significant predictor of aortic plaque area fraction in a mouse model of CRF-accelerated atherosclerosis (4).

In cultured MCD3 cells, high urea concentration increased levels of ROS and the oxidative stress marker 8-oxoguanine (5). Based upon these findings, we hypothesized that elevated urea levels could be a contributing factor linking CRF, oxidative stress, insulin resistance, and atherosclerosis.

In the present study, we have shown that urea at concentrations seen in early and late CRF induce ROS production in cultured 3T3-L1 adipocytes, which increases modification of insulin signaling molecules by O-GlcNAc and reduces insulin-stimulated IRS and Akt phosphorylation and glucose transport. These negative signaling changes directly correlate with decreased insulin sensitivity and elevated levels of insulin resistance-associated adipokines. Similarly, uremic mice display increased ROS production, modification of insulin signaling molecules by O-GlcNAc, and increased expression of the insulin resistance-associated adipokines RBP4 and resistin in visceral adipose tissue. Moreover, uremic mice are insulin resistant and glucose intolerant. Treatment with the SOD/catalase mimetic (MnTBAP) normalizes O-GlcNAc modification of insulin signaling molecules in visceral fat, corrects systemic insulin resistance and glucose intolerance, and normalizes the expression of RBP4 resistin and adiponectin.

Although a number of abnormalities in uremic patients' blood other than urea could give rise to insulin resistance (12-17), consistent with urea's direct effect in 3T3L1 adipocytes, urea infusion in normal animals induced the same degree of insulin resistance and elevated insulin resistance-associated adipokines as that seen in CRF. Treatment with the SOD/catalase mimetic MnTBAP again prevented urea-induced insulin resistance 
A

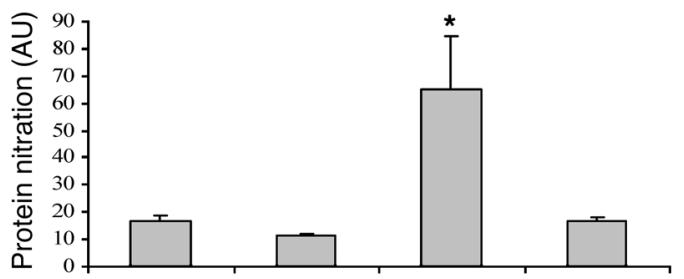

B

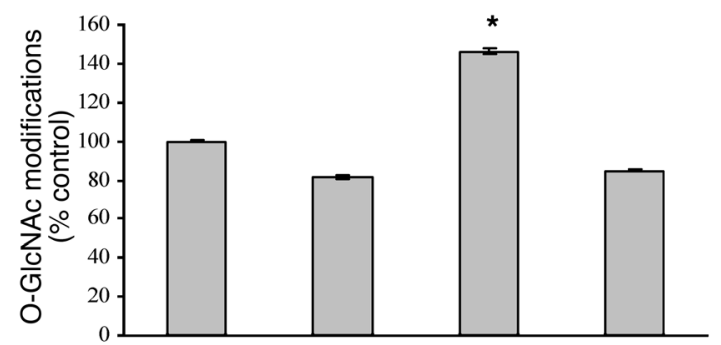

C

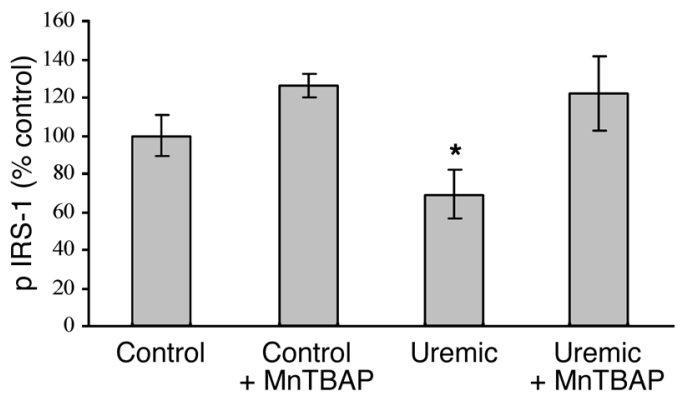

and normalized insulin resistance-associated adipokine levels. Taken together, these data demonstrate that the proximate cause of insulin resistance in the urea-infused animal is ROS and that under these conditions, urea alone is sufficient to induce the same degree of insulin resistance as that seen in CRF.

The findings reported here may also provide a molecular explanation for the insulin resistance of CRF. Since urea can increase carbamylation and carbonylation of intracellular proteins (5), it is likely that these posttranslational modifications are responsible for altered function of cytosolic, nuclear, and mitochondrial proteins involved in the regulation of mitochondrial ROS production. Like urea, hyperglycemia also increases intracellular oxidative stress, modification of insulin signaling molecules by O-GlcNAc, and insulin resistance in arterial endothelial cells (35). Additive or synergistic effects of urea and hyperglycemia might explain the 2 -fold increase in 5-year mortality of ESRD patients with diabetes compared with those without diabetes (36).

\section{Figure 10}

Treatment of uremic mice with a SOD/catalase mimetic normalizes insulin resistance-associated adipokine levels in adipose tissue and in plasma. Treated uremic mice and treated controls received MnTBAP i.p. for 2 weeks. (A) Relative expression of RBP4 and resistin in epididymal adipose tissue of untreated and MnTBAP-treated control and uremic mice measured by $\mathrm{qPCR}$. The control values are shown as 1.0. (B) Plasma levels of RBP4 and resistin measured in the plasma of the untreated and MnTBAP-treated control mice and in the plasma of untreated and MnTBAP-treated CRF mice by semiquantitative Western blot or ELISA, respectively. Each bar represents the mean \pm SEM of 7 mice per group. ${ }^{*} P<0.01$ compared with controls.

\section{Figure 9}

Treatment of uremic mice with a SOD/catalase mimetic normalizes oxidative stress, IRS-1 O-GIcNAc modification, and IRS-1 pTyr in epididymal fat. Treated uremic mice and treated controls received MnTBAP i.p. for 2 weeks. (A) Oxidative stress was quantified by immunoblotting of epididymal adipose tissue protein using anti-3-nitrotyrosine antibody and normalized for total protein by blotting with anti- $\beta$-actin antibody. (B) IP: Western blot analysis of uremia-induced O-GlcNAc modification of IRS-1 and (C) IRS-1 Tyr phosphorylation in epididymal adipose tissue. Levels of IRS-1 modification in epididymal adipose tissue from untreated control mice are shown as $100 \%$ in bar graphs. $n=5,{ }^{*} P<0.01$ compared with controls. Data represent mean + SEM.

In summary, the observations reported here show that increased levels of urea, long considered to have negligible toxicity in patients with CRF, can cause insulin resistance in vitro and in vivo as a consequence of increased ROS generation. Treatment with a $\mathrm{SOD} /$ catalase mimetic normalizes insulin resistance and glucose intolerance in mice with CRF. Urea infusion in normal animals induces insulin resistance and elevates insulin resistance-associated adipokines, and treatment with a SOD/catalase mimetic prevents these urea-induced abnormalities. Because insulin resistance is an important independent cardiovascular risk factor, novel therapeutics that directly target urea-induced ROS and insulin resistance may potentially help reduce the high morbidity and mortality caused by ESRD.

\section{Methods}

Materials. DMEM, nonessential amino acids, FBS, antibiotics, insulin, and urea were from Sigma-Aldrich. The urea used in these experiments was certified to be free of LPS and heavy metals. MnTBAP was from Calbiochem; protein A-sepharose and CM-H2DCFDA were from Invitrogen. Plasma insulin and resistin were measured with monoclonal antibody-based sandwich enzyme-linked immunosorbent assays (Linco Research). Antibodies and reagents used were as follows: anti-phosphotyrosine, anti-IRS-1, antipS636-IRS-1 (UBI); anti-Akt, anti-S473-Akt (Cell Signaling Technology); anti-O-linked glycosylation RL-2 (Affinity Bioreagents); anti-RBP4 (Alexis Biochemical); and anti-3-nitrotyrosine (Upstate).
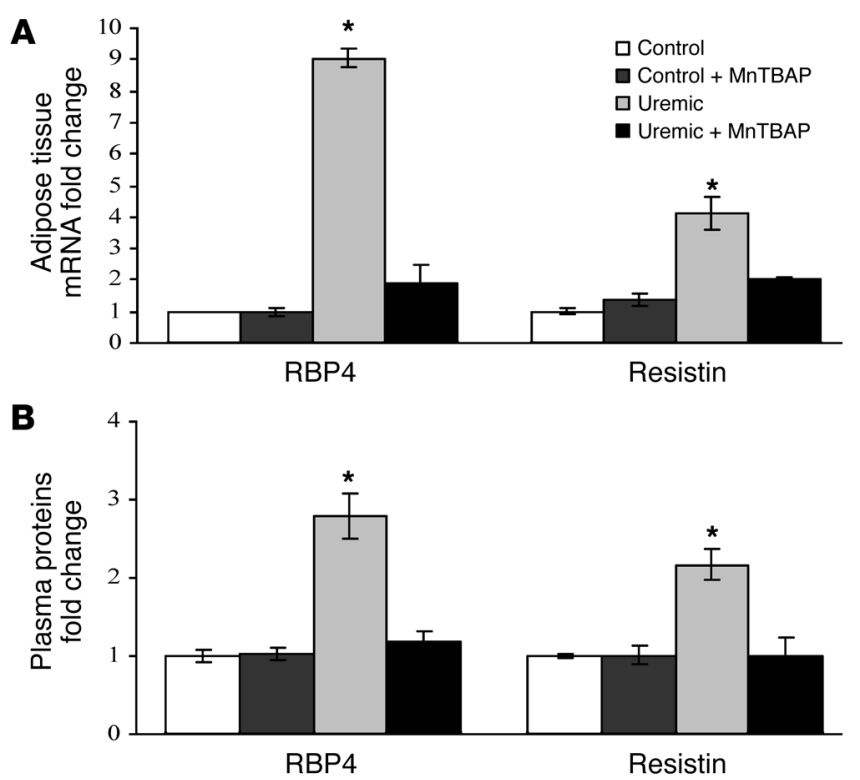


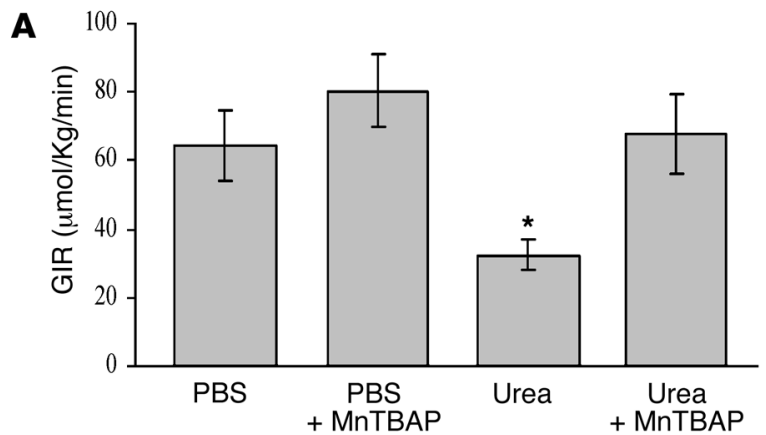

B
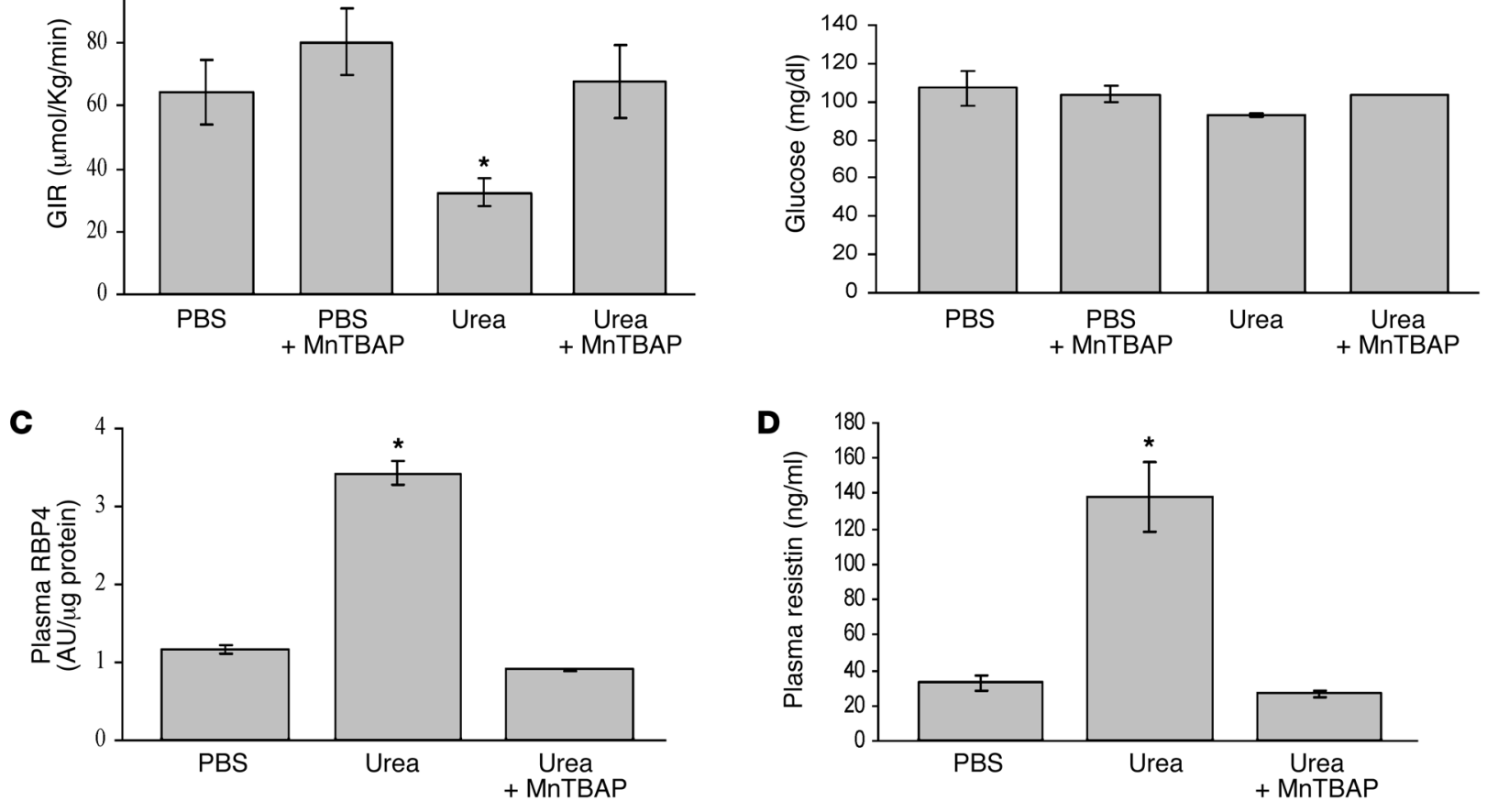

\section{Figure 11}

Urea infusion induces insulin resistance and elevated insulin resistance-associated adipokines in normal rats. (A) GIR necessary to maintain euglycemia at 120 minutes of EU clamps of rats infused with PBS or urea with or without MnTBAP treatment. (B) Plasma glucose levels at 120 minutes of EU clamps of rats infused with PBS or urea with or without MnTBAP treatment. (C) Plasma levels of RBP4 at 120 minutes of euglycemichyperglycemic clamps in rats infused with PBS or urea with or without MnTBAP treatment. (D) Plasma levels of resistin at 120 minutes of euglycemic-hyperglycemic clamps in rats infused with PBS or urea with or without MnTBAP treatment. All results represent mean \pm SEM of 5 animals per group. ${ }^{*} P<0.01$ compared with controls.

Mouse models. C57BL/6J wild-type mice (Harlan Italy S.r.1.) were housed in a temperature-controlled facility $\left(21^{\circ} \mathrm{C}-23^{\circ} \mathrm{C}\right)$ with a 12 -hour light/12-hour dark cycle. The mice were allowed free access to food and water. The experiments were performed according to the principles stated in the Italian law on animal experiments and were approved by the Animal Experiments Inspectorate, Ministry of University, Rome, Italy. At 7 weeks of age, the mice were randomly allocated to $5 / 6$ nephrectomy and no surgery. A mixture of $0.079 \mathrm{mg} / \mathrm{ml}$ fentanyl, $2.5 \mathrm{mg} / \mathrm{ml}$ fluanisone, and $1.25 \mathrm{mg} / \mathrm{ml}$ midazolam (Hypnorm/Dormicum) at a dose of 0.08 to $0.10 \mathrm{ml} / 10 \mathrm{~g}$ body weight was given subcutaneously for anesthesia. Moderate uremia was induced by a 2 -step surgical procedure (37). In brief, the upper and lower poles of the right kidney were resected. One week later, the left kidney was removed after ligation of the renal blood vessels and the ureter. Control animals were subjected to a sham operation that included decapsulation of both kidneys. Special care was taken to avoid damage to the adrenals. A randomized group of 5/6 nephrectomized mice and their controls were injected i.p. with MnTBAP at a dose of $10 \mathrm{mg} / \mathrm{kg}$ for 15 days starting immediately after the second surgical procedure. For measuring food intake, mice were housed individually and food intake was estimated by measuring the weight of powdered food remaining in feeding chambers designed to maximize spill capture. After the first surgery, the CFR mice were fed ad libitum with powdered mouse diet (LabDiet) that was weighed and replaced daily, and control mice were pair-fed with CFR mice. Body weight was monitored every week. Plasma fasting insulin levels were determined weekly using monoclonal antibody-based sandwich enzyme-linked immunosorbent assays (Linco Research). Three weeks after the first surgical procedure, animals underwent glucose and insulin tolerance tests. The following day, after terminal blood sampling, animals were killed with a lethal dose of sodium pentobarbital (100 mg/kg; Nembutal, Abbott Laboratories).

Blood chemistries. Mouse blood glucose was determined by testing $5 \mu \mathrm{l}$ of tail-vein blood using an Accu-Chek (Roche) active blood glucose-monitoring system. Every week, BUN was analyzed using the L-Type UN Kit (Wako) based on an enzymatic assay utilizing urease and glutamate dehydrogenase. Plasma insulin and plasma resistin were measured with monoclonal antibody-based sandwich enzyme-linked immunosorbent assays (Linco Research or R\&D Systems Europa). Plasma RBP4 was determined by semiquantitative Western blot using anti-RBP4 antibody (Alexis Biochemical).

Insulin and glucose tolerance tests. Insulin and glucose tolerance tests were performed as described previously (38). Blood glucose was determined by Accu-Chek (Roche) active blood glucose-monitoring system, and plasma insulin levels were measured by ELISA (Linco Research).

Cell culture. 3T3-L1 murine fibroblasts were propagated and differentiated as described previously (39). In brief, the cells were propagated in FBS (DMEM containing $5 \mathrm{mM}$ glucose, $10 \% \mathrm{FBS}$, and penicillin/streptomycin $[100 \mathrm{units} / \mathrm{ml}$ each]) and allowed to reach confluence. After 2 days (day 0 ), the medium was changed to DM1 (containing FBS and $160 \mathrm{nM}$ insulin, $250 \mu \mathrm{M}$ dexamethasone, and $0.5 \mathrm{mM}$ 3-isobutyl-1-methylxanthine). Two days later (day 2), the medium was switched to DM2 (FBS containing $160 \mathrm{nM}$ insulin). After another 2 days, the cells were switched backed to FBS for 2 days, and then they were incubated in medium containing $20 \mathrm{mM}$ urea for 48 hours. Mannitol was used as an osmotic control for the highest urea concentration. To test urea toxicity effect on differentiated 3T3-L1, cell toxicity was determined using a Cell Toxicity Colorimetric Assay Kit from Sigma-Aldrich. 
Measurement of [1-3H]2-deoxyglucose uptake. [3H]2-deoxyglucose uptake was performed as described previously (39). In brief, the cells were glucose starved for 30 minutes. Insulin was then added for 5 minutes, followed by addition of the labeled glucose in the continued presence of the indicated amount of insulin. Glucose transport assays were carried out in a volume of $1 \mathrm{ml}$ (Krebs-Ringer/HEPES buffer, $\mathrm{pH}$ 7.4) in a 3.5-cm dish for 25 minutes at $37^{\circ} \mathrm{C}$. The concentration of 2-deoxyglucose was $50 \mu \mathrm{M}$ with $0.33 \mu \mathrm{Ci}$ of $[3 \mathrm{H}] 2$-deoxyglucose $/ \mathrm{ml}$. After terminating the transport assay with 3 washes of ice-cold assay buffer, each plate was solubilized in $1 \mathrm{ml}$ of $0.1 \mathrm{M} \mathrm{NaOH}$ and quenched with $50 \mu \mathrm{l}$ of concentrated $\mathrm{HCl}$. A $0.9-\mathrm{ml}$ aliquot was removed for determination of radioactivity by liquid scintillation counting, and $50 \mu \mathrm{l}$ aliquots were used for measurement of protein using a bicinchoninic acid (BCA) assay. Glucose uptake remained linear within the first 30 minutes. Each measurement at the indicated urea concentrations represents the average of 8 independent measurements performed on 5 separate occasions with different cell preparations.

Immunoprecipitation and Western blotting. At the end of treatments, 3T3-L1 adipocytes were incubated in the presence or absence of $5 \mathrm{nM}$ insulin for 10 minutes. Epididymal adipose tissue was isolated from control and uremic mice. Cells/tissue lysis, immunoprecipitation, and Western blotting were performed as described previously. Cell lysates or tissue protein extracts were cleared by preimmune IgG plus protein A agarose beads for 2 hours, and the supernatants were immunoprecipitated by the indicated antibodies with a $50 \%$ slurry of protein A agarose beads overnight at $4{ }^{\circ} \mathrm{C}$. After washing with buffer containing $50 \mathrm{mM}$ Tris, $\mathrm{pH} 7.5,150 \mathrm{mM} \mathrm{NaCl}$, $1 \% \mathrm{NP}-40$, and $0.5 \%$ deoxycholate with protease inhibitors, proteins were released and separated on 10\% SDS-PAGE gels. Membranes blotted with anti-phosphotyrosine or phosphoactive antibodies were stripped and reprobed with primary antibodies to verify expression levels. Protein phosphorylation levels were normalized to the matching densitometric values of nonphosphorylated proteins.

Adenoviral vectors. Adenoviral vectors were generated as described previously (35). Adenoviruses were incubated with serum-free medium containing $0.5 \mu \mathrm{g} / \mathrm{ml}$ polylysine for 100 minutes prior to the addition to PBSwashed 3T3-L1 adipocytes. After 4 hours, the medium was replaced with fresh medium and cells were cultured for an additional 2 days (39).

$R T$ reaction and real-time quantitative PCR. Total RNA from treated cells or mouse adipose tissue was extracted using the RNeasy Mini Kit (QIAGEN). Total RNA was then isolated following the manufacturer's instructions. The mRNA was reverse transcribed by SuperScript III First Strand Synthesis System (Invitrogen). Experiments were performed in quadruplicate in optical 96-well reaction plates on an iCycler iQ Multi- color Real-Time PCR Detector (Bio-Rad) with iQ SYBR green supermix (Bio-Rad). Expression levels of RBP4, resistin, and adiponectin were normalized to $\beta$-actin levels in the same sample. Melting curves were analyzed to ensure that fluorescence signals solely reflected specific amplicons. PCR conditions were as follows: 7 minutes at $95^{\circ} \mathrm{C}$ and 45 cycles of 30 seconds at $95^{\circ} \mathrm{C}$ and 30 seconds at $60^{\circ} \mathrm{C}$.

EU clamp. EU clamps were performed essentially as described by Kraegen et al. (40). In brief, 2-month-old male Wistar rats were implanted with indwelling catheters in the left carotid artery, right jugular vein, and femoral vein. The rats were allowed to recover from the surgery for 5 days and then were either infused with isotonic or urea $(10 \mathrm{mg} / \mathrm{kg} / \mathrm{h})$ for 48 hours using a microdialysis pump. A separate group of rats was injected i.p. with MnTBAP at a dose of $10 \mathrm{mg} / \mathrm{kg}$ for 7 days before and during the 48 -hour isotonic or urea infusion.

Prior to the EU clamp, the rats were fasted overnight and a standard 2-hour EU clamp was conducted using a primed and continuous infusion of human insulin (Humulin) at a rate of $1.67 \mathrm{mU} / \mathrm{kg} / \mathrm{min}$ coupled with a variable infusion of $20 \%$ glucose to maintain blood glucose concentrations at approximately $100 \mathrm{mg} / \mathrm{dl}$.

Statistics. Data were analyzed using 1-factor ANOVA to compare the means of all the groups. The Tukey-Kramer multiple comparisons procedure was used to determine which pairs of means were different. A $P$ value of less than 0.01 was considered statistically significant.

\section{Acknowledgments}

The authors thank Philipp Scherer for thoughtful comments and suggestions during the course of this project. This work was supported by grants from Fondazione Cassa di Risparmio di Puglia, AIC Puglia (to I. Giardino) and by National Institute of Diabetes and Digestive and Kidney Diseases NIH grants R01 DK74153-01 (to M. Brownlee) and R37 DK33823 (to J.E. Pessin).

Received for publication March 30, 2009, and accepted in revised form October 7, 2009.

Address correspondence to: Michael Brownlee, Diabetes Research Center, Albert Einstein College of Medicine, 1300 Morris Park Avenue, Bronx, New York 10461, USA. Phone: (718) 430-3636; Fax: (718) 430-8570; E-mail: brownlee@aecom.yu.edu. Or to: Ida Giardino, Dipartimento di Scienze Biomediche, Università degli Studi di Foggia, Viale Pinto 1 O.O.R.R., Foggia, Italy. Phone: 390881-736006; Fax: 39-0881-733718; E-mail: ig@unifg.it.
1. Johnson WJ, Hagge WW, Wagoner RD, Dinapoli $\mathrm{RP}$, Rosevear JW. Effects of urea loading in patients with far-advanced renal failure. Mayo Clin Proc. 1972;47(1):21-29.

2. Eknoyan G, et al. Effect of dialysis dose and membrane flux in maintenance hemodialysis. $N$ Engl J Med. 2002;347(25):2010-2019.

3. Kjellstrand CM, et al. Short daily haemodialysis: survival in 415 patients treated for 1006 patient-years. Nephrol Dial Transplant. 2008;23(10):3283-3289.

4. Ivanovski $\mathrm{O}$, et al. The antioxidant $\mathrm{N}$-acetylcysteine prevents accelerated atherosclerosis in uremic apolipoprotein E knockout mice. Kidney Int. 2005;67(6):2288-2294.

5. Zhang Z, Dmitrieva NI, Park JH, Levine RL, Burg $\mathrm{MB}$. High urea and $\mathrm{NaCl}$ carbonylate proteins in renal cells in culture and in vivo, and high urea causes 8-oxoguanine lesions in their DNA. Proc Natl Acad Sci U S A. 2004;101(25):9491-9496.

6. Vaziri ND. Oxidative stress in uremia: Nature, mechanisms, and potential consequences. Semin Nephrol. 2004;24(5):469-473.
7. Brownlee M. Biochemistry and molecular cell biology of diabetic complications. Nature. 2001;414(6865):813-820

8. Yang $\mathrm{X}$, et al. Phosphoinositide signalling links OGlcNAc transferase to insulin resistance. Nature. 2008;451(7181):964-969.

9. Bodlaj G, Ber J, Pichler R, Biesenbach G. Prevalence, severity and predictors of HOMA-estimated insulin resistance in diabetic and nondiabetic patients with end-stage renal disease. $J$ Nephrol. 2006;19(5):607-612.

10. Lorenzo C, et al. Relation of low glomerula filtration rate to metabolic disorders in individuals without diabetes and with normoalalbiminuria. Clin J Am Soc Nephrol. 2008;3(3):783-789.

11. Takenaka T, Kanno Y, Ohno Y, Suzuki H. Key role of insulin resistance in vascular injury among hemodialysis patients. Metabolism. 2007;56(2):153-159

12. May RC, Kelly RA, Mitch WE. Mechanisms for defects in muscle protein metabolism in rats with chronic uremia. Influence of metabolic acidosis.
J Clin Invest. 1987;79(4):1099-1103.

13. Saad MJ, et al. Regulation of insulin receptor substrate- 1 in liver and muscle of animal models of insulin resistance. J Clin Invest. 1992;90(5):1839-1849.

14. Saad MJ, Folli F, Kahn JA, Kahn CR. Modulation of insulin receptor, insulin receptor substrate-1, and phosphatidylinositol 3-kinase in liver and muscle of dexamethasone-treated rats. J Clin Invest. 1993;92(4):2065-2072.

15. Song YH, et al. Muscle-specific expression of IGF-1 blocks angiotensin II-induced skeletal muscle wasting. J Clin Invest. 2005;115(2):451-458.

16. Hotamisligil GS, Peraldi P, Budavari A, Ellis R, White MF, Spiegelman BM. IRS-1-mediated inhibition of insulin receptor tyrosine kinase activity in TNF-alpha- and obesity-induced insulin resistance. Science. 1996;271(5249):665-668.

17. Bailey JL, Zheng B, Hu Z, Price SR, Mitch WE. Chronic kidney disease causes defects in signaling through the insulin receptor substrate/phosphatidylinositol 3-kinase/Akt pathway: implications for muscle atrophy. J Am Soc Nephrol. 2006;17(5):1388-1394. 
18. Brown MS, Goldstein JL. Selective versus total insulin resistance: a pathogenic paradox. Cell Metab. 2008;7(2):95-96.

19. Yaturu S, et al. Plasma and urine levels of resistin and adiponectin in chronic kidney disease. Cytokine. 2007;37(1):1-5.

20. Ziegelmeier M, et al. Serum levels of adipokine retinol-binding protein-4 in relation to renal function. Diabetes Care. 2007;30(10):2588-2592.

21. Furukawa $S$, et al. Increased oxidative stress in obesity and its impact on metabolic syndrome. J Clin Invest. 2004;114(12):1752-1761.

22. Day BJ, Fridovich I, Crapo JD. Manganic porphyrins possess catalase activity and protect endothelial cells against hydrogen peroxide-mediated injury. Arch Biochem Biophys. 1997;347(2):256-262.

23. Clark PW, Jenkins AB, Kraegen EW. Pentobarbital reduces basal liver glucose output and its insulin suppression in rats. Am J Physiol. 1990;258(4 pt 1):E701-E707.

24. Choi CS, et al. Overexpression of uncoupling protein 3 in skeletal muscle protects against fat-induced insulin resistance. $J$ Clin Invest. 2007;117(7):1995-2003.

25. Yip J, Facchini FS, Reaven GM. Resistance to insulin-mediated glucose disposal as a predictor of cardiovascular disease. J Clin Endocrinol Metab.
1998;83(8):2773-2776.

26. Hanley AJ, Williams K, Stern MP, Haffner SM. Homeostasis model assessment of IR in relation to the incidence of cardiovascular disease: the San Antonio Heart Study. Diabetes Care. 2002;25(7):1177-1184.

27. Foley RN, Parfrey PS, Sarnak MJ. Clinical epidemiology of cardiovascular disease in chronic renal disease. Am J Kidney Dis. 1998;32(5 suppl 3):S112-S119.

28. Schiffri EL, Lipman ML, Mann JF. Chronic kidney disease: effects on the cardiovascular system. Circulation. 2007;116(1):85-97.

29. Nishizawa Y, et al. Intima-media thickness of carotid artery predicts cardiovascular mortality in hemodialysis patients. Am J Kidney Dis. 2003;41(3 suppl 1):S76-S79.

30. Guerin AP, London GM, Marchais SJ, Metivier F. Arterial stiffening and vascular calcifications in end-stage renal disease. Nephrol Dial Transplant 2000;15(7):1014-1021.

31. Surana SP, Keithi-Reddy SR, Singh AK. Diffuse vascular calcification in a dialysis patient. Kidney Int. 2008;73(7):890-894.

32. Ienaga K, Mikami H, Yokozawa T. First indications demonstrating the preventive effects of NZ-419, a novel intrinsic antioxidant, on the initiation and/ or progression of chronic renal failure in rats. Biol
Pharm Bull. 2009;32(7):1204-1208.

33. Galle J, Seibold S. Has the time come to use antioxidant therapy in uraemic patients? Nephrol Dial Transplant. 2003;18(8):1452-1455.

34. Gordon CA, Himmelfarb J. Antioxidant therapy in uremia: evidence-based medicine? Semin Dial. 2004;17(5):327-332.

35. Du X, et al. Insulin resistance reduces arterial prostacyclin synthase and eNOS activities by increasing endothelial fatty acid oxidation. J Clin Invest. 2006;116(4):1071-1080.

36. Koch M, Hollenbeck M, Trapp R, Kulas W, Grabensee $\mathrm{B}$. Value of diabetes as an independent predictor of death in subjects with end-stage renal disease. Med Klin (Munich). 2006;101(12):933-937.

37. Massy ZA, et al. Uremia accelerates both atherosclerosis and arterial calcification in apolipoprotein $\mathrm{E}$ knockout mice. J Am Soc Nephrol. 2005;16(1):109-116.

38. Brüning JC, et al. Development of a novel polygenic model of NIDDM in mice heterozygous for IR and IRS-1 null alleles. Cell. 1997;88(4):561-572.

39. Lin Y, et al. The hyperglycemia-induced inflammatory response in adipocytes: the role of reactive oxygen species. J Biol Chem. 2005;280(6):4617-4626.

40. Kraegen EW, James DE, Bennett SP, Chisholm DJ. In vivo insulin sensitivity in the rat determined by euglycemic clamp. Am J Physiol. 1983;245(1):E1-E7. 